\title{
Variação da curvatura da base de braquetes "Straight-Wire": estudo comparativo entre quatro marcas comerciais
}

\author{
Luciana de Paula GONTIJO*, Enio Tonani MAZZIEIRO**, Janes Landre JÚNIOR***
}

\begin{abstract}
Resumo
Este trabalho objetivou avaliar as qualidades arquiteturais das bases dos braquetes "StraightWire" de quatro marcas comerciais (Morelli, Abzil Lancer, Unitek e A-Company) comparando as suas curvaturas médias no sentido oclusogengival e mesiodistal. As curvaturas das bases dos braquetes foram medidas por meio de uma máquina de medidas universais da Société Genevoise D' Instruments de Physique, marca CSIP, modelo MUL-300, e os dados encontrados foram transferidos para um software de desenho AutoCAD 2000, gerando superfícies em ambiente tridimensional, a partir das quais se mediu a curvatura e o raio das bases dos acessórios ortodônticos. Os resultados demonstraram que a curvatura da base de cada braquete variou em sua extensão e que para um mesmo elemento dentário, as curvaturas e seus respectivos raios variaram entre as marcas comerciais analisadas.
\end{abstract}

Palavras-chave: Braquetes ortodônticos. Straight-Wire. Base do braquete.

\section{INTRODUÇÃO}

O aparelho ortodôntico mais difundido e utilizado atualmente foi desenvolvido por Andrews ${ }^{1,2,3,4}$. Baseado em seus estudos sobre as Seis Chaves da oclusão o autor instituiu modificações substanciais nos braquetes do tipo "Edgewise", incorporando em sua estrutura as dobras de $1^{\mathrm{a}}, 2^{\mathrm{a}}$ e $3^{\text {a }}$ ordem, objetivando atingir o controle tridimensional do movimento dentário e, conseqüentemente uma finalização ortodôntica adequada. Este sistema é chamado de "Straight-Wire",,2,3,4.

A suposição teórica implícita nesse sistema, é que a orientação dos dentes em uma boa oclusão e a morfologia dentária apresentam características similares entre os diversos pacientes, permitindo o uso generalizado de braquetes pré-torqueados, pré-angulados e com desvios compensatórios (in set e off set) das espessuras dos dentes, em conjunto com arcos retos, alcançando automaticamente uma boa oclusão.

Andrews $s^{1,2,3,4}$ afirmou que existe uma variação pequena e não importante na morfologia dentária entre os indivíduos, que essa diferença morfológica obedecia à curva de distribuição normal numa população, e que ela não influenciaria no correto posicionamento dos braquetes durante as colagens. Porém, segundo Morrow ${ }^{12}$ esta abordagem está sendo contestada por vários autores, que têm

* Aluna do curso de Mestrado em Ortodontia do COP-PUC-Minas.

** Doutor em Ortodontia, Coordenador do Mestrado em Ortodontia do COP-PUC-Minas.

*** Doutor em Engenharia Mecânica, professor do Departamento de Engenharia da PUC-Minas. 
reavaliado o assunto.

Pesquisadores como Taylor $^{13}$, Meyer e Nelson $^{10}$, Dellinger ${ }^{7}$, Bryant et al. ${ }^{6}$, Germane et al. ${ }^{9}$, Balut et al. ${ }^{5}$, encontraram uma considerável variação na curvatura da superfície vestibular dos dentes, levando ao questionamento do tratamento com a técnica do arco contínuo, com o sistema de braquetes "Straight-Wire".

Considerando-se que a base metálica do braquete é colada, com sistemas adesivos na superfície vestibular dos dentes, torna-se importante determinar uma curvatura ideal dessa base, pressupondo uma melhor adaptação à anatomia dentária, e conseqüentemente uma melhor adesão e retenção ao dente, podendo o braquete trabalhar eficientemente nas três dimensões do espaço.

A literatura científica apresenta-se escassa de publicações a respeito da curvatura das bases dos braquetes. Verificando-se os catálogos das indústrias fabricantes de acessórios ortodônticos, observa-se um número reduzido de informações pertinentes à angulação da curvatura da base de braquetes, tanto no sentido mesiodistal quanto oclusogengival. Suspeita-se que ainda sejam utilizadas as medidas determinadas por Andrews $s^{1,2,3,4}$ que registrou a morfologia vestibular da coroa, na dimensão incisogengival, segurando um gabarito geométrico com círculos de vários diâmetros contra o contorno do dente. Porém, é claro para Mithke e Melsen ${ }^{11}$ e também para nós, que a complexidade da superfície vestibular dentária não pode ser retratada corretamente por meio de seções circulares utilizando um método extremamente impreciso.

Observações clínicas e as várias correções de posicionamento dentário durante a fase de finalização dos casos nos levaram a questionar a padronização dos tratamentos e a utilização dos sistemas "Straight-Wire". Associado a esses fatos, a grande oferta de diversas marcas e modelos de acessórios ortodônticos nos induziram a outros questionamentos: seriam as bases dos braquetes de diversas marcas comerciais semelhantes em suas curvaturas? Seriam essas curvaturas similares àquelas apresentadas pelas superfícies vestibulares dos dentes para os quais cada braquete foi produzido? Quais implicações clínicas poderíamos observar se não existissem tais concordâncias?

Dessa forma, esse trabalho idealizou, em uma primeira etapa, um estudo comparativo mais detalhado entre as bases dos braquetes metálicos de diversas marcas comerciais, analisando-se o grau de suas curvaturas mesiodistal e oclusogengival. Em etapas subseqüentes procuraremos responder às demais questões.

\section{MATERIAIS E MÉTODOS \\ Materiais}

Para a realização deste trabalho, utilizou-se um total de 240 braquetes das marcas comerciais Morelli (modelo: 10.10.901-CRTZ-01- lote 20000809, prescrição Roth-.022"x.030”), Abzil Lancer (modelo: Kirium Line .022"x.030", prescrição Roth), Unitek (modelo: Gemini mesh .022"x.030 prescrição Roth ref: 119-701) e ACompany (modelo: True Straight-Wire, tamanho médio, prescrição Roth .022"x.030"), obtidos através dos seus representantes comerciais.

Três bocas completas (segundo pré-molar a segundo pré-molar) de cada marca comercial foram analisadas.

\section{Métodos}

Para a obtenção das medidas, os braquetes foram incorporados em gesso pedra, produzindo blocos, com as suas bases voltadas para cima (Fig. 1). Após a incorporação dos braquetes nos blocos de gesso, estes foram adaptados e fixados, por meio de garras, em uma máquina de medidas universais, impedindo qualquer movimentação (Fig. 2), o que poderia inferir erros.

A máquina para medidas universais utilizada foi desenvolvida pela Société Genevoise D' Instruments de Physique, marca CSIP, modelo MUL300 (Fig. 3), com resolução de 0.5 micrômetros para o eixo Z, 0.025 milímetros para o eixo Y e 0.02 milímetros para o eixo $\mathrm{X}$. 


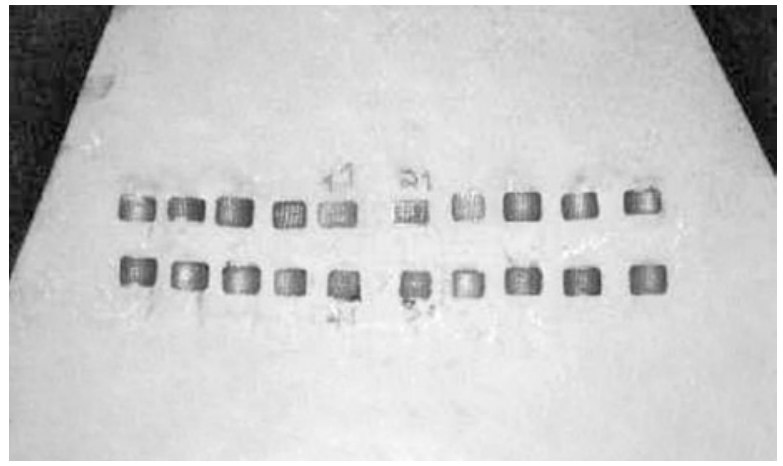

FIGURA 1-Braquetes incorporados no gesso, com as superfícies de suas bases expostas, para a realização das medições na máquina de medidas universais.

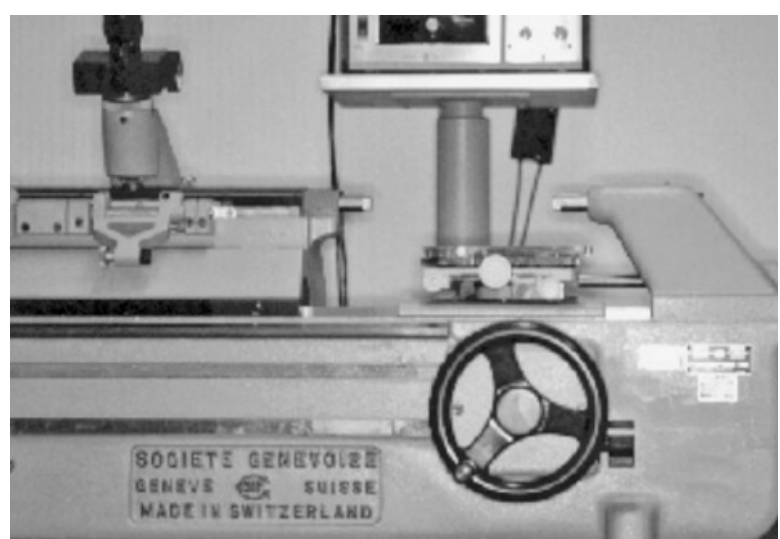

FIGURA 3 - Máquina para medidas universais, desenvolvida pela Société Genevoise D' Instruments de Physique, marca CSIP, modelo MUL-300.

A fim de minimizar os erros das medidas, dois pesquisadores efetuaram as avaliações, em três momentos cada um. Posteriormente, os valores encontrados em cada avaliação foram confrontados entre sí, determinando-se os valores médios para cada braquete analisado. As medidas foram tomadas a cada $1 \mathrm{~mm}$ de distância, tanto no sentido horizontal como no vertical do braquete.

A partir das medições, obtiveram-se os pontos cartesianos (posição $\mathrm{x}, \mathrm{y}, \mathrm{z}$ de cada ponto da malha impressa no braquete) que foram transferidos para o software de desenho AutoCAD 2000 da Autodesk $^{\circledR}$ que, por possuir funções matemáticas apropriadas, possibilitou gerar superfícies em ambiente tridimensional (Fig. 4).

Para a determinação das curvaturas, identificaram-se cinco pontos nas superfícies tridimensio-

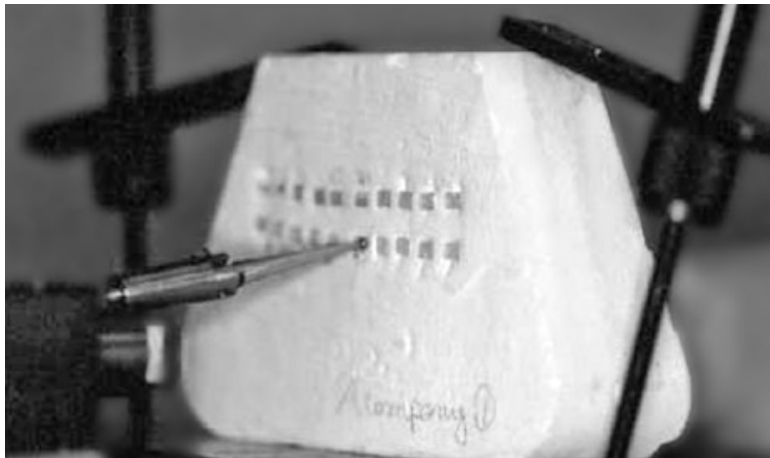

FIGURA 2 - Posicionamento e fixação do modelo de gesso na máquina de medidas universais.

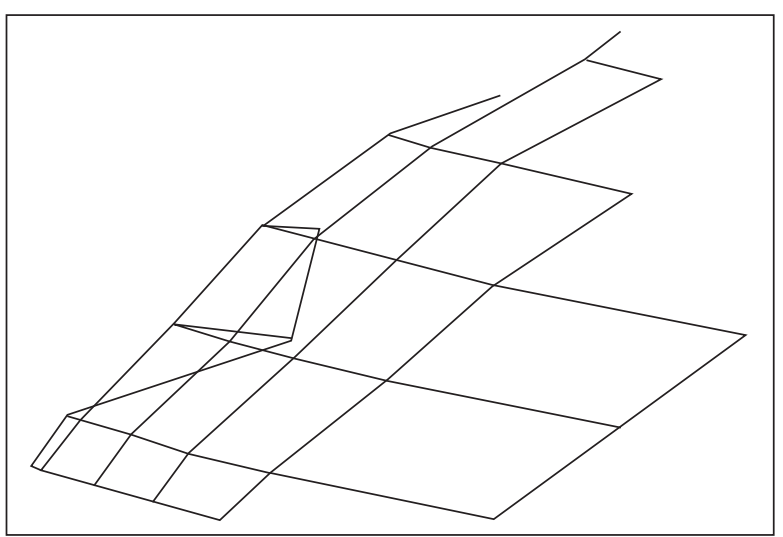

FIGURA 4 - Imagem da superfície tridimensional da base do braquete do elemento dentário 21, gerada pelo software de desenho AutoCAD 2000, Autodesk ${ }^{\circledR}$.

nais dos braquetes: 1) os pontos médios de cada dimensão mesiodistal, localizados nas bordas superior e inferior da malha; 2) os pontos médios de cada dimensão oclusogengival localizados nas bordas laterais esquerda e direita 3) e um ponto central, localizado no centro da malha do braquete. A partir de um eixo cartesiano fixo tomou-se a variação angular de cada um desses pontos, denominando-os de $\alpha 1, \alpha 2, \alpha 3, \beta 1, \beta 2, \beta 3$ (Fig. 5).

Os ângulos identificados por alfa representam a variação angular entre os pontos no sentido mesiodistal do braquete e os ângulos identificados por beta representam a variação angular entre os pontos no sentido oclusogengival. Os resultados encontrados foram apresentados em forma de coordenadas cartesianas e posteriormente calculados os raios das curvaturas das bases dos braquetes. 
Todos os braquetes (de $2^{\circ}$ pré-molar a $2^{\circ}$ prémolar) foram avaliados, porém optou-se por apresentar apenas os resultados referentes aos braquetes 21 e 33, uma vez que a sua produção industrial é seriada e não individualizada, condição última

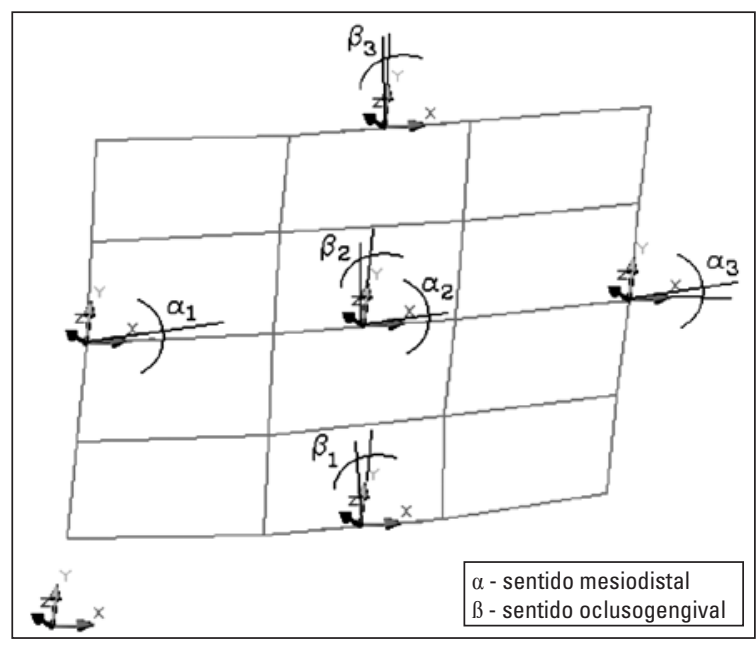

FIGURA 5 - Desenho tridimensional da base do braquete para o elemento dental 21 , onde foram determinados os cinco pontos com seus respectivos ângulos de avaliação $\alpha 1, \alpha 2, \alpha 3, \beta 1, \beta 2, \beta 3$.

Tabela 1 - Valores dos ângulos obtidos para cada ponto determinado na superfície do braquete do dente 21 , nas quatro marcas comerciais avaliadas.

\begin{tabular}{c|c|c|c|c|c|c|}
\hline Marca & $\alpha 1$ & $\alpha 2$ & $\alpha 3$ & $\beta 1$ & $\beta 2$ & $\beta 3$ \\
\hline MORELLI & 1,26 & 2,48 & 1,26 & 0,65 & 2,73 & 0,65 \\
\hline ABZIL & 1,53 & 0,30 & 1,53 & 0,12 & 0,20 & 0,12 \\
\hline A Company & 0,34 & 0,42 & 0,34 & 1,13 & 1,76 & 1,13 \\
\hline UNITEK & 0,68 & 0,77 & 0,68 & 0,14 & 0,54 & 0,14 \\
\hline
\end{tabular}

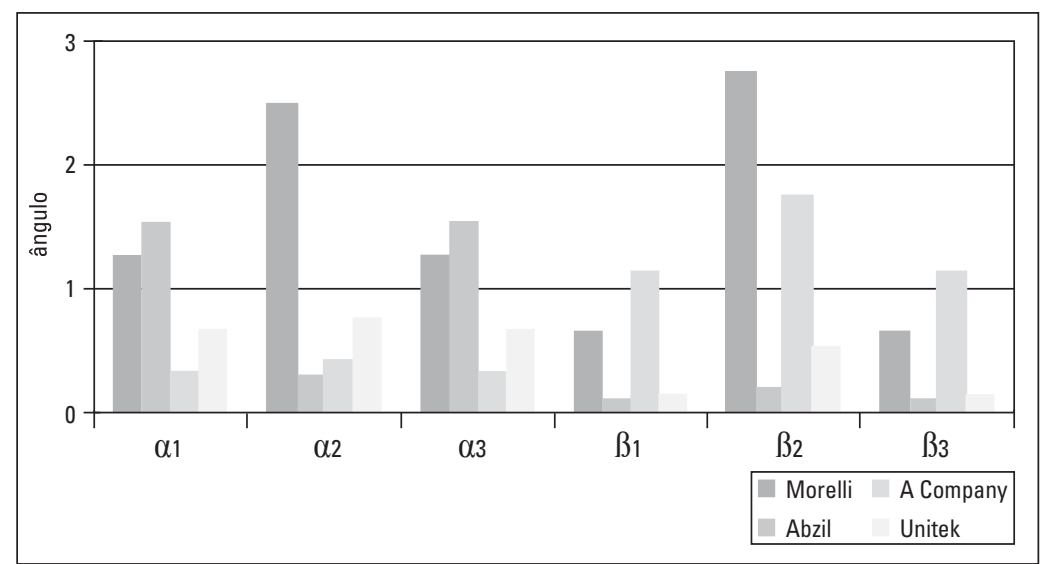

GRÁFICO 1 - Valores comparativos dos ângulos $\alpha$ e $ß$ do braquete do dente 21, para cada marca comercial. em que se admitiria dispersões de braquete para braquete.

Em uma produção seriada, o que varia é apenas a curvatura dada em função do dente ou grupos de dentes para o qual o acessório servirá. As eventuais dispersões existentes entre os braquetes tendem a ser uniformes dentro de uma mesma marca comercial, já que, caso fossem diferentes, o equipamento deveria ser calibrado para cada um dos braquetes a ser produzido, inviabilizando ou dificultando a produção.

\section{RESULTADOS}

Após a obtenção dos ângulos de cada ponto fixo pré-determinado $(\alpha 1, \alpha 2, \alpha 3, \beta 1, \beta 2, \beta 3)$, em relação ao eixo cartesiano, foi possível fazer uma comparação entre os ângulos dos braquetes das marcas comerciais utilizadas no estudo. Os resultados comparativos entre as marcas comerciais das avaliações angulares e dos raios de curvaturas dos acessórios ortodônticos podem ser observados nas tabelas e nos gráficos descritos abaixo.

A tabela 1 e o gráfico 1 apresentam os valores angulares obtidos para o braquete fabricado para o elemento dental 21, nos cinco pontos determinados para as avaliações dos ângulos $\alpha$ e $\beta$ e a comparação entre as marcas avaliadas.

A tabela 2 e o gráfico 2 apresentam os valores dos ângulos $\alpha \mathrm{e}$ $\beta$ obtidos para o braquete do elemento dental 33, nos cinco pontos determinados e a comparação entre as marcas desses valores.

A comparação entre os ângulos das diversas marcas comerciais demonstrou a inexistência de uma padronização da curvatura das bases. Cada marca comercial apresentou valores diferentes de conformação. 
Tabela 2 - Valores dos ângulos obtidos para cada ponto determinado na superfície do braquete do dente 33 , nas quatro marcas comerciais avaliadas .

Marca

MORELLI

ABZIL

Acompany

UNITEK

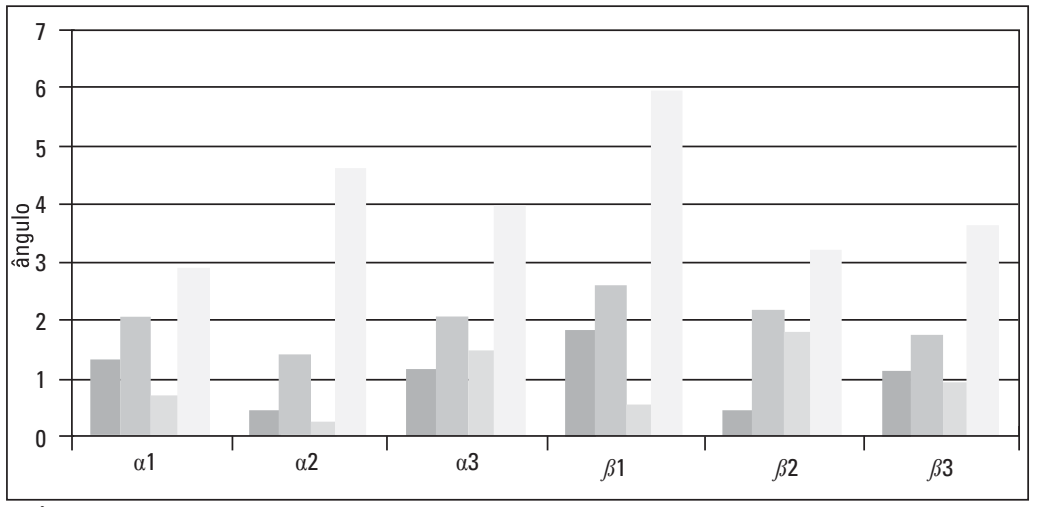

GRÁFICO 2 - Valores comparativos dos ângulos $\alpha$ e ß do braquete do dente 33, para cada marca comercial. característica vital para um efetivo funcionamento do aparelho "Straight-Wire".

Durante o desenvolvimento do sistema "Straight-Wire", Andrews ${ }^{1,2,3,4}$ registrou a morfologia vestibular da coroa dos dentes, na dimensão oclusogengival, utilizando um gabarito geométrico com círculos de vários diâmetros contra o contorno do dente. A partir dessas medições projetou-se as primeiras bases dos braquetes deste sistema. Porém, obviamente que a complexidade das superfícies vestibulares dentárias não podem ser retratadas por meio de seções circulares, devido às variações anatômicas das suas superfícies e à pouca precisão deste método utilizado ${ }^{11}$.

A literatura científica apresenta poucos trabalhos relacionados às medições das curvaturas das superfícies dentárias. Além disso, existem contradições em relação às conclusões dessas pesquisas. Andrews ${ }^{1,2,3}$ afirma que as variações anatômicas das superfícies vestibulares dos diversos dentes não apresentam grandes alterações dentro de uma população e que essas variações obedecem à curva de distribuição normal. Esse fato viabilizaria a utilização de braquetes com padrões médios de curvaturas nos sentidos mesiodistal e oclusogengival. Em contrapartida, Taylor ${ }^{13}$, Morrow ${ }^{12}$, Dellinger $^{7}$, Bryant et al. ${ }^{6}$, Germane, Bentley e Isaacson ${ }^{9}$ concordam em seus resultados, afirmando que a variabilidade biológica da anatomia dentária, sobretudo no aspecto de sua superfície vestibular, apresenta-se extremamente grande.

Essa ambigüidade de resultados torna-se preocupante quanto ao aspecto ortodôntico. A utilização de braquetes do sistema "StraightWire" onde os acessórios são produzidos em série, 


\begin{tabular}{|c|c|c|}
\hline \multicolumn{3}{|c|}{ Tabela 3 - Valores dos raios das } \\
\hline curvaturas das bases dos braquetes do dente 21. \\
\hline Marca & $\begin{array}{c}\text { Valor do raio } \\
\text { Mésiodistal }\end{array}$ & $\begin{array}{c}\text { Valor do raio Oclu- } \\
\text { sogengival }\end{array}$ \\
\hline Morelli & $12.82 \mathrm{~mm}$ & Infinito \\
\hline Unitek & $15.92 \mathrm{~mm}$ & $15 \mathrm{~mm}$ \\
\hline Abzil & $10.56 \mathrm{~mm}$ & Infinito \\
\hline A Company & $16.53 \mathrm{~mm}$ & $13.5 \mathrm{~mm}$ \\
\hline
\end{tabular}

dentro de padrões estabelecidos, pressupõe que todos os pacientes apresentem dentes similares na sua característica anatômica. A pouca informação sobre as curvaturas dos braquetes, aliada à quase inexistência de trabalhos sobre anatomia dentária, nos leva a suspeitar que até hoje as curvaturas das bases dos braquetes são fabricadas de acordo com o estudo de Andrews $s^{1,2,3,4}$ ou por tentativas aleatórias das indústrias fabricantes.

O fato da curvatura da base do braquete não se apresentar similar à superfície do dente dificultará o seu correto posicionamento durante a colagem, podendo alterar o funcionamento ideal do acessório. Dellinger ${ }^{7}$ afirmou que para se obter um correto posicionamento do braquete na superfície vestibular do dente, o ideal é que a curvatura da base do acessório fosse bastante similar à curvatura da superfície vestibular de cada dente individualmente. De acordo com Balut et al. ${ }^{5}$, fatores como o erro no posicionamento do braquete e as irregularidades dos dentes podem dificultar a obtenção do perfeito alinhamento das cristas marginais, dos pontos de contato e da correta posição das raízes ao final do tratamento com o uso do aparelho ortodôntico pré-ajustado.

Além disso, Germane et al. ${ }^{9}$ mostraram que o efetivo torque do braquete, também é influenciado pela diferença entre a morfologia do dente e a base do acessório e que qualquer braquete préajustado irá produzir variações no longo eixo vestibulolingual ou na quantidade do torque quando colocados em diferentes alturas do mesmo dente. Essas alterações no torque empregado nos dentes,

\begin{tabular}{|c|c|c|}
\hline \multicolumn{3}{|c|}{ Tabela 4 - Valores dos raios das } \\
\hline curvaturas das bases dos braquetes do dente 33. \\
\hline Marca & $\begin{array}{c}\text { Valor do raio } \\
\text { mésiodistal }\end{array}$ & $\begin{array}{c}\text { Valor do raio } \\
\text { Oclusogengival }\end{array}$ \\
\hline Morelli & $2.82 \mathrm{~mm}$ & infinito \\
\hline Unitek & $3.58 \mathrm{~mm}$ & $13 \mathrm{~mm}$ \\
\hline Abzil & $1.92 \mathrm{~mm}$ & $14.5 \mathrm{~mm}$ \\
\hline A Company & $4.66 \mathrm{~mm}$ & $13 \mathrm{~mm}$ \\
\hline
\end{tabular}

decorrente da dificuldade de posicionamento ou erros durante a colagem, também foram relatadas por autores como Meyer e Nelson ${ }^{10}$, Balut et al. ${ }^{5} \mathrm{e}$ Miethke e Melsen ${ }^{11}$. Uma diferença de até $15^{\circ}$ no torque de um dente pode acontecer se o braquete for deslocado, na sua colagem, em $3 \mathrm{~mm}$ da posição ideal ${ }^{10}$.

A preocupação em relação à eficácia do sistema "Straight-Wire" aliada à pouca informação sobre as bases dos braquetes nos levou à realização do presente trabalho. $\mathrm{O}$ intuito científico, em nenhum momento, foi o de indicar a superioridade de determinada marca comercial. Intencionou-se apenas estudar as características arquiteturais dos diversos braquetes disponíveis, verificando as possíveis diferenças em suas conformações. Portanto, decidiu-se calcular as curvaturas das bases de braquetes nacionais e importados.

Procurando manter a isenção em relação aos fabricantes, durante a seleção das marcas analisadas, enviou-se cartas para várias empresas e revendedoras, solicitando a doação dos braquetes para a pesquisa. Foram avaliados os braquetes das empresas ou revendedores que responderam dentro do prazo estipulado. Dessa forma, os resultados desse trabalho se restringem apenas a essas marcas, não podendo ser extrapolados para as demais existentes no mercado, uma vez que os resultados mostraram uma grande variabilidade entre os fabricantes.

Para a medição da curvatura da base dos braquetes utilizou-se a máquina de medidas universais marca CSPI, modelo MUL-300 disponível no departamento de engenharia mecânica da PUC-Minas. 
Os dados foram coletados em forma de coordenadas cartesianas, facilitando a transferência para um programa de desenho tridimensional computadorizado (AutoCAD 2000) onde estes foram trabalhados.

O sistema de coordenadas cartesianas permite identificar as distâncias horizontal, vertical e a profundidade de um corpo em relação a um ponto de referência, que é denominado de origem do sistema cartesiano. Esta origem é identificada com os valores $0,0,0$. Transferidos os dados, tornou-se possível a modelagem das bases dos acessórios ortodônticos no ambiente AutoCAD e a determinação dos vários ângulos $\alpha$ e $\beta$ (Fig. 5).

A localização desses ângulos, no ponto médio das extremidades das superfícies externas dos braquetes e um ponto central à sua base, permitiu estabelecer as curvaturas mesiodistal e oclusogengival passando pelo longo-eixo vertical do braquete e, horizontalmente, pelo meio da sua estrutura. Dessa forma, intencionou-se aproximar ao máximo a avaliação dessas curvaturas às referências clínicas utilizadas durante as colagens desses acessórios. Segundo Andrews ${ }^{1,2,3}$, os acessórios devem ser colados com o seu longo-eixo vertical coincidente com o dentário, no centro da coroa clínica e sem inclinações no longo-eixo horizontal. Quando corretamente posicionado, os longos-eixos estariam perpendiculares entre si e no meio da coroa clínica do dente. Dessa forma, pressupõe-se a similaridade entre essas curvaturas.

Após a análise dos dados obtidos, constatouse que para uma mesma marca comercial houve variação entre os ângulos de cada ponto fixo predeterminado (Tab. 1, 2), significando que as curvaturas das bases dos braquetes diferiam em sua extensão. Esse resultado era esperado pois, os dentes apresentam curvaturas diferentes nas suas superfícies vestibulares e, conseqüentemente, também os braquetes.

Comparando-se o mesmo ponto entre as marcas estudadas, observou-se uma discrepância nos resultados, indicando que as curvaturas das bases dos braquetes da Morelli, Abzil Lancer, A-Company e Unitek, não são iguais, para o mesmo elemento dentário, tanto no sentido mesiodistal, quanto no oclusogengival. Por meio da análise dos raios das curvaturas das bases dos braquetes (Tab. 3), pode-se observar que para o braquete do dente 21, a marca A-Company apresentou o maior raio no sentido mesiodistal, o que implicou em uma curvatura mais suave, seguida, respectivamente, da Unitek, Morelli e Abzil. Portanto, a Abzil apresentou para esse braquete em específico, a maior curvatura. Analisando os valores para o braquete do dente 33, o maior raio no sentido mésiodistal foi observado na marca A-Company, seguida da Unitek, Morelli, Abzil (Tab. 4).

Com relação à curvatura no sentido oclusogengival, observa-se que os braquetes para os dentes 21 e 33 da Morelli e o 21 da Abzil possuem raio infinito, o que significa que a superfície nesse sentido apresenta-se plana. A ausência de curvatura oclusogengival na Morelli e na Abzil provavelmente se deve ao processo de fabricação (usinagem) desses modelos de acessórios testados. Na usinagem, a incorporação dessas curvaturas são mais difíceis, diferente do processo de fabricação dos braquetes injetados onde, a partir de um molde contendo a conformação desejada dos acessórios, a injeção do metal origina os braquetes do tipo monobloco.

A ausência de curvatura oclusogengival da base do braquete pode dificultar uma adaptação perfeita ao dente. De acordo com Dellinger ${ }^{7}$, para se obter um correto posicionamento do braquete na superfície vestibular do dente, o ideal é que a curvatura da base do acessório seja bastante similar à curvatura da superfície vestibular de cada dente individualmente, facilitando a colagem na sua posição ideal.

A importância da curvatura composta, vertical (oclusogengival) e horizontal (mésiodistal) da base do braquete é enfatizada por Andrews1, ${ }^{1,3,4}$, que considerou essa uma das características espe- 
cíficas vitais para um efetivo funcionamento do aparelho "Straight- Wire".

Diante dos resultados descritivos apresentados, observa-se que não há uma padronização de medidas das curvaturas das bases dos braquetes entre as marcas pesquisadas. Contudo, nesse momento, torna-se impossível afirmar a superioridade de um braquete sobre outro com relação à curvatura pois, para isso, torna-se necessário conhecer a curvatura média da superfície vestibular de cada dente, no sentido mesiodistal e oclusogengival, para qual fabrica-se o braquete. Contudo, a inexistência da curvatura oclusogengival nos braquetes da Morelli e da Abzil (dente 21) pode representar uma dificuldade de adaptação durante as colagens.

Além disso, numa extrapolação desses dados, podemos supor a possível existência de dificuldades de adaptação dos braquetes de diferentes marcas comerciais ao serem colados em um determinado dente ou paciente. A diferença na adaptação à superfície dentária das diversas marcas proporcionará variadas espessuras na interface de colagem dente-braquete e conseqüentemente, possíveis discrepâncias nos resultados aos testes de resistência à tração e ao torque empregado aos dentes. Podemos sugerir também, que a utilização de marcas diferentes pode proporcionar resultados diferentes em relação ao posicionamento dentário quando utilizados em dentes com anatomia semelhante.

No aspecto clínico, os resultados encontrados permitem-nos afirmar que os sistemas "StraightWire", embora sejam eficientes acessórios ortodônticos, não posicionam todos os dentes de forma ideal. A idéia divulgada de que o tratamento ortodôntico se torna mais simples e de fácil execução quando se utiliza braquetes pré-torqueados e pré-angulados contrapõe-se às dificuldades de colagem dos acessórios, decorrente das diferenças entre as diversas marcas comerciais, às variações anatômicas dos dentes e à habilidade inerente de cada ortodontista na execução das diversas etapas do tratamento.
Muitas dessas deficiências podem ser contornadas com a execução de dobras nos fios e com a aplicação de diversos princípios mecânicos. Para tal, torna-se fundamental um amplo entendimento, por parte dos ortodontistas, de diversas técnicas e mecânicas. A Ortodontia, como ciência, não deve ser encarada como simples sistemas de braquetes, onde se opta pela utilização do pré-ajustado ou do padrão, mas como a capacidade do ortodontista em diagnosticar, planejar e executar corretamente os seus casos. O conhecimento e a habilidade do profissional deverão sempre superar o sistema de braquetes escolhido.

\section{CONCLUSÃO}

Baseados na metodologia empregada, podemos concluir que não existiu uma padronização das curvaturas das bases dos braquetes das marcas analisadas. Cada fabricante apresentou valores dos raios de curvaturas diferentes, tanto no sentido mesiodistal quanto oclusogengival.

\section{ANÁLISE DO CONSULTOR}

Quero parabenizar o autor pelo trabalho, pois demonstra preocupação com relação à idéia que se passa, muitas vezes, por aí de que agora tudo é fácil (aparelhos inteligentes) e que não há mais necessidade de se aprender a dar dobras num fio porque os braquetes tudo resolvem.

É descabível, num curso de especialização, "facilitar a vida do aluno e/ou dos professores", permitindo que se forme indivíduos sem habilidade manual e conhecimento suficiente, para uma boa finalização do tratamento ortodôntico. O aluno deve utilizar os braquetes modernos sem dúvida, pois são uma grande evolução, mas, durante o curso, deve utilizar, principalmente, o braquete edgewise "básico", para realmente ser um ORTODONTISTA.

Arno Locks

Enviado em: Agosto de 2002

Revisado e aceito: Novembro de 2002 


\title{
Straight-wire base brackets curvature: analysis of four differents manufactures
}

\author{
Abstract \\ The objective of this study was to determine the average occlusogingival and mesiodistal curvature of the \\ bases of straight-wire brackets. Brackets from four different manufactures were utilized: Morelli, Abzil Lancer, \\ Unitek and A-Company. The measurements of the curvature of the bases of the brackets were, initially, taken \\ with a universal instrument of the Société Genevoise D'Instruments de Physique, known as CSIP, model MUL- \\ 300. The data obtained was transferred to an AUTOCAD 2000 software, which generated a three dimensional \\ image, where the curvature and the radius of the bases were finally measured. The results demonstrated a great \\ variability of these measurements among the four different brands for the same bracket.
}

Key words: Orthodontic brackets. Straight-wire. Base of the bracket.

\section{REFERÊNCIAS}

1. ANDREWS, L. F. The straight- wire appliance: arch form, wire bending \& an experiment. J Clin Orthod, Boulder, v. 10, no. 8 p. 581-588, Ago. 1976.

2. ANDREWS, L. F. The straight- wire appliance: explained and compared. J Clin Orthod, Boulder, v. 10, no. 3, p. 174-195, Mar. 1976.

3. ANDREWS, L. F. The straight- wire appliance: origin, controversy, commentary. J Clin Orthod, Boulder, v. 10, no. 2, p. 99-114, Feb. 1976.

4. ANDREWS, L. F. Straight wire: the concept and appliance. 2nd ed. San Diego: L. A. Wells, 1989.

5. BALUT, N.; KLAPPER, L.; SANDRIK, J.; BOWMAN, D. Variations in bracket placement in preajusted orthodontic appliance. Am J Orthod Dentofacial Orthop, St. Louis, v. 102, no. 1, p. $62-$ 67, July 1992.

6. BRYANT, R. M.; SADOWISKY, D. M. D.; M.; HAZELRIG, J. B. Variability in the three morphologic features of the permanent maxillary central incisor. Am J Orthod Dentofacial Orthop St. Louis, v. 86, no.1, p. 25-32, July 1984

7. DELLINGER, E. L. A scientific assessment of the straight-wire appliance. Am J Orthod Dentofacial Orthop, St. Louis, v. 73, no. 3, p. 290-299, Mar. 1978

8. GERMANE, N.; BENTLEY. B. E.; ISSACSON. R. J. Three biologic variables modifying facial lingual tooth angulations by straight-wire appliance. Am J Orthod Dentofacial Orthop, St. Louis, v. 96, no. 4, p. 312-319, Oct. 1989

9. GERMANE, N.; BENTLEY, B.; ISAACSON, R. J.; REVERE, J. H. The morphology of canines in relation to preajusted appliances. Angle Orthod, Appleton, v. 60, no. 1, p. 49-54. 1990.

10. MEYER, M.; NELSON, G. Preajusted edgewise appliance, theory and practice. Am J Orthod, St. Louis, v. 73, no. 5 p. 485-498, May 1978.

11. MIETHKE, R.; MELSEN, B. Effect of variation in tooth morphology and bracket position on first and third order correction with preadjusted appliances. Am J Orthod Dentofacial Orthop, St. Louis, v. 116, no. 3, p. 329-335, Mar. 1999.

12. MORROW, J. B. The angular variability of the facial surface of the human dentition; an evaluation of the morphologic assumptions implied in various "straight-wire"techniques. 1978. 94 f. Dissertação (Mestrado em Ciência da Odontologia)St. Louis University, St. Louis, 1978.

13. SOCIETÉ GENEVOISE D'INSTRUMENTS DE PHYSIQUE. Technical instructions for shop gauge measuring machine. [S.I.: s. n. 2000?]. 1CSIP, type. MUL-300.

14. TAYLOR, R. M. S. Variation in form of human teeth: II. An anthropologic and forensic study of maxillary canines. J Dent Res, Chicago, v. 48, no. 2, p.173-186, Mar. 1969.

\section{Endereço para correspondência}

Enio Tonani Mazzieiro

PUC-Minas - Av. Dom José Gaspar 500, prédio 46, Coração Eucarístico

CEP - 30535-610 - Belo Horizonte - MG, Brasil

mazzieiro@pucminas.br 